University of Wollongong

Research Online

2013

Information systems for the social well-being of senior Australians

Lois Burgess

University of Wollongong, lburgess@uow.edu.au

Helen Hasan

University of Wollongong, hasan@uow.edu.au

Carole Alcock

University of Wollongong, caroleal@uow.edu.au

Follow this and additional works at: https://ro.uow.edu.au/ahsri

Research Online is the open access institutional repository for the University of Wollongong. For further information contact the UOW Library: research-pubs@uow.edu.au 


\title{
Information systems for the social well-being of senior Australians
}

\author{
Abstract \\ In most developed countries the ageing population is placing a severe strain on health systems and \\ national budgets. In meeting this challenge, e-Health initiatives seek medically-focused ICT solutions for \\ improved health services that enable senior citizens to remain living at home longer. A literature review \\ and interviews with health-care providers reveal that significant factors affecting the well-being of the \\ elderly are isolation and loneliness. In this paper we report on the first stages of a study on the digital \\ literacy of seniors and the potential development of social media to meet the capabilities of people as \\ they age. Focus groups with senior citizen computer club members tell us that older folk are become \\ more digitally literate. As social media becomes more usable and acceptable, we propose that online \\ communities for senior citizens may have significant health benefits. As this is a multifaceted emergent \\ phenomenon we apply concepts from Complexity Theory to our analysis and to the design of future \\ research on this topic using an action research methodology.

\section{Publication Details} \\ L. Burgess, H. Hasan \& C. Alcock, "Information systems for the social well-being of senior Australians", \\ Building Sustainable Information Systems: Proceedings of the 2012 International Conference on \\ Information Systems Development. Springer New York, United States, (2013) 89-100.
}




\title{
Information Systems for the Social Wellbeing of Senior Australians
}

\author{
Lois Burgess \\ University of Wollongong Australia, lburgess@uow.edu.au \\ Helen Hasan \\ University of Wollongong Australia hasan@uow.edu.au \\ Carole Alcock \\ University of Wollongong Australia caroleal@uow.edu.au
}

\begin{abstract}
In most developed countries the ageing population is placing a severe strain on health systems and national budgets. In meeting this challenge, e-Health initiatives seek medically-focused ICT solutions for improved health services that enable senior citizens to remain living at home longer. A literature review and interviews with health-care providers reveal that significant factors affecting the well-being of the elderly are isolation and loneliness. In this paper we report on the first stages of a study on the digital literacy of seniors and the potential development of social media to meet the capabilities of people as they age. Focus groups with senior citizen computer club members tell us that older folk are become more digitally literate. As social media becomes more usable and acceptable, we propose that online communities for senior citizens may have significant health benefits. As this is a multifaceted emergent phenomenon we apply concepts from Complexity Theory to our analysis and to the design of future research on this topic using an action research methodology.
\end{abstract}

\section{Introduction}

In Australia, as in most of the developed world, the ageing population is creating challenges for the adequate provision of affordable healthcare for increasing numbers of senior citizens at home, in self-managed units or in residential care. The ageing population is placing severe strain on the health system and the nation's budget. E-health is perceived as a means to provide a high level of online medical service while reducing the economic burden and enabling the elderly to remain at home longer. There are also enormous benefits to be gained through e-health for those living in regional and remote areas. Significant effort has been put into research and development of technical solutions to medical issues including monitoring devices and Internet-based consultations. Less research has been conducted into how to enhance the emotional and social needs of the ageing population.

Our research is motivated by literature reporting that loneliness and isolation are among the main problems encountered by folk living well into their 80 s and 90 s. Those still in their home receive basic medical and support services either through e-health systems or professional visits but their lack of mobility restricts 
their ability to interact socially. Those who move into independent self-managed units or full-residential institutions are often dislocated from family and friends.

Although they did not grow up with digital technologies, those now in their 60 s and 70s are increasingly more computer and Internet savvy. Many have been active users at work or elsewhere while others in retirement are catching up, using email, social media and online services to connect with family and friends and access information. It is not clear however, how this will equip them for the later stages of life when they will be increasing more reliant on the Internet for their social interaction but have reduced physical and mental capability.

The exploratory study reported here seeks answers to two related questions. To what extent can the elderly use information systems to address issues of loneliness and isolation? How can socio-technical systems be established using emerging Web 2.0 applications to meet the disparate needs of isolated elderly users? By mean of literature review, interviews with aged care providers and a focus group with members of a seniors computing club research explores the ways in which senior citizens currently participate in online communities, their capabilities for doing so and the potential benefits of involvement in online communities for isolated senior citizens. As this is an emergent phenomenon, we explain how we apply concepts from Complexity Theory to our analysis of this exploratory phase of the research. We conclude the paper with the design of future research on this topic using an action research methodology.

\section{Literature Review}

\subsection{Isolation and Loneliness}

Despite the global interconnectedness provided by the Internet, isolation and loneliness is an increasing social problem. Norrie [26] reports that isolation and loneliness pose an increasing threat to the health of Australians, many of whom are cut off from friends and locals by ill-conceived urban design. According to research cited by the report between 1984 and 2005, the percentage of Australians who said they did not have any trusted friends rose from $4 \%$ to $6 \%$, while the percentage who felt they could not call on locals for help increased from $11 \%$ to $13 \%$,. The figures are expected to worsen with the rise in the number of single-person households. The report concludes that "it's now recognised that loneliness is up there with high blood pressure, lack of exercise, obesity, and smoking as an indicator of shortened life expectancy.

Isolation appears to be a universal problem in ageing populations [14]. One UK digital media champion, Martha Fox, expressed concern that "over three million people aged over 65 don't see another person in a week" and believed that technology could help address this problem [8]. This is supported in a study on the use of online communities by older people, which found a positive association between a sense of belonging to an online community, sense of community and link to well-being [32]. Coughlan [11] also describes the particular health risks for the 
elderly in England where more than half of people over the age of 75 are living alone and about one in 10 says he or she suffers from "intense" loneliness. A lack of social interaction can make old people more vulnerable to depression and to problems such as excessive drinking, poor diet and a reduction in exercise. A study of 1,300 people aged 65 and over [17], found that $35 \%$ of participants were lonely, with $9 \%$ describing it as painful and $6 \%$ as intrusive. $34 \%$ had a nonintegrated social network with wellbeing, depressed mood and hopelessness all independently associated with both loneliness and non-integrated social networks. While younger people routinely make use of social media to stay connected it is often assumed that the elderly are not inclined to do so, particularly those who have never used computers. However we suggest that this is changing.

\subsection{Digital Literacy of the Elderly}

There has been a strong focus on teaching seniors basic internet skills and there is considerable literature relating to this. The AHRC [4] Report emphasises education, training and provision of appropriate technology to achieve effective Internet access. Parry [29] states that teaching mobile web literacy is as important as teaching basic literacy. Several research papers, [19 34 35] focus on training seniors in Internet use. Internet literacy programs for older users are regarded as an important first step, but more is required.

Recent Australian research into Internet use by female seniors [28] pointed to the need for access to training, technical assistance and information as important for this group. Palmer [28] refers to earlier studies of elderly participants suggesting that lower levels of education, lower income levels and workforce participation might be factors contributing to their lower usage of Internet based services. The most common use was for email. Lack of knowledge was perceived as a major barrier. Some had had bad experiences and felt disillusioned. Lack of services and not knowing where to find help were a concern.. Users had a generally positive view of the Internet's impact on well-being, while non-users thought it would have a negative effect. A concern expressed in the report's conclusion was that, while, in this study, non-users experienced little inconvenience at present, they were concerned that lack of access might be a problem in the future [28].Training aimed at improving digital literacy skills was among the report's recommendations, as was consultation with seniors on e-government services.

In a small Australian study, Mellor et al. [23] considered a group of twenty residents in a nursing home, who reported a generally positive experience from the use of computers. As there were discrepancies in the findings, it was suggested that the impact on wellbeing was more complex than could be inferred from these results. This clearly warrants further study among a wider group.

Access to information services by the elderly is another area of importance. One report [4] expressed the view that digital technologies offered the potential for providing greater access to both government and business information services. Improved access to education and services at locations and in formats that otherwise might have been difficult to access was also stressed. Concern was 
raised regarding equity of access, with some older Australians not enjoying the standards that others take for granted. The report highlighted the potential for both older Australians and those with disabilities, to extend their access to information services of every kind due to the inherent nature of digital technologies

Designing systems with a variety of interfaces that older people will use seems a logical objective, although some researchers have suggested that age is less a discriminating factor than is commonly thought. In a study by Chung et al. [10], factors affecting perceptions of online community participation were investigated using the Technology Acceptance Model (TAM). One finding was that "the relationships among perceived ease of use, perceived usefulness and intention to participate in online communities do not change with age." Ease of use was no more important to older users than it was to younger users. These findings have implications for developers. Older users were concerned about privacy issues and this might be a factor influencing their participation in social media sites. Ease of navigation and content relevant to the target audience, regardless of age were important. Perceived quality of sites and web design are, it seems, important to older and younger users alike.

\subsection{E-Health, Seniors and Social Media}

When considering the needs of older Australians, much focus has been directed towards e-health to assist at-home, isolated seniors, particularly the over 80s. This is not surprising given the potential of developments in this area. In his reports on Australia's Digital Economy, Paul Budde [6 7] describes e-health as potentially one of the "key killer apps linking e-health developments to the National Broadband Network, two significant areas being early diagnosis and post-treatment patient monitoring provided at home.

It is clear from the Australian demographic that e-health is important. In the recent government report "Australia 2050: future challenges" [2], the emphasis is on "an ageing and growing population". Consequent on this, a significant rise is predicted in aged care spending, related to the increasing number of people over 85 , likely to be in residential care or with disabilities requiring special care. E-health applications may help to reduce the need for residential care. The Report states that social media may hold some promise in this regard.

Social networking is seen as useful in combating loneliness and isolation: "U1timately, virtual communities can combat social isolation by offering a new channel for older Australians to form support networks, maintain contact with friends and family, and participate in different parts of the community" [3]. A recent study suggests that social media collaborations in relation to specific diseases (in this case, Crohn's disease among teens) can be extended to many of the diseases of older age groups: diabetes, heart disease, psoriasis and some cancers [18].

Reports on use of the Internet and social media in the US in 2010 [1 21 30] indicate that the average usage of Internet social media among users over 50 had nearly doubled in the preceding year, from $22 \%$ to $42 \%$ of those surveyed. Among those using social networking sites, the findings recorded $47 \%$ of 50 to 64 year 
olds and $26 \%$ of those 65 years and older. Numbers using MySpace, Facebook and Linkedin had grown by $88 \%$ among $50-64$ year olds; $100 \%$ among older users (65 and over), whereas growth among younger users (18-29) (already representing $86 \%$ of all users) was only $13 \%$. Email was still the main medium of communication among older users.

The literature reports conflicting findings on the usefulness of social media in overcoming isolation, loneliness and depression. In their 2006 UK study, Dickinson and Gregor [12] suggested that "computer use had no demonstrated impact on well-being in older adults." Participants in a study conducted by Erickson in 2011 [14], reported mixed opinions on the value of facebook as a "community", with most seeing it as a medium to passively view what others were doing. A more recent Canadian study of seniors over 60 [15], however, suggested that the Internet promoted "higher perceptions of self-efficacy" among seniors using the Internet regularly over those who did not. Similar findings were reported in a US Study [16 31], which reported positive results, with $20 \%$ reduction in depression, among elderly American Internet users. This study looked at survey responses from 7,000 American retirees, aged over 55 years. It concluded that there were significant health outcomes to be had from expanding Internet adoption in this age group, with potential economic savings as well. Etchemendy et al [13] claim that ICT can be helpful in reducing negative moods and isolation and thus can be efficacious and effective resources for improving the quality of life in elderly.According to Norval et al. [27], research suggests that communication platforms that complement existing telecare systems could be designed to provide significant emotional support for older adults. However, it is clear that this is still an under-researched area where further work is needed [14].

The study that we have found to most closely relate to our work is one by Ballantyne et al [5] who describe a qualitative pilot project that implemented an internet social networking intervention with six older people aged 69 to 85 years recruited from a community aged care programme. The researchers evaluated the effect it had on older people's experience of temporal loneliness. The findings from this project demonstrated that the utilisation of a social networking site has the potential to reduce loneliness in older people. Four major themes emerged from their inductive analysis of the data which were: the participants' experience of loneliness; technology as an enabler; providing a supportive environment; and connectivity. We are encouraged not only by the positive results of the study but also by the inductive approach taken, which allowed for emergence of issues and outcomes.

\section{Theoretical Underpinning}

Our literature review demonstrates the complex and multidisciplinary nature of our topic. Most e-health research follows a traditional scientific method of enquiry that is well ordered as it should be. Most websites for seniors are currently created top-down where government or civil 'experts' train, advise or organise older people who are assumed to have low digital skills and knowledge. In contrast, what 
appears to be needed to overcome loneliness is to engage seniors in meaningful online communities and activities that are created bottom up by the senior citizens themselves with assistance, facilitation and encouragement where needed. We thus turn to concepts from Complexity Theory such as self-direction, self organisation and emergence.

Complexity Theory is concerned with the behaviour over time and space of complex systems. Complexity science deals with complex adaptive systems that are fluidly changing collections of distributed interacting components that react to both their environments and to one another. Complex systems have a history; they evolve and their past is co-responsible for their present behaviour. Elements in the system can be ignorant of the behaviour of the system as a whole responding only to what is available to it locally.

Within complex contexts principles of emergence, co-evolution, pattern formation, self-direction, and self-organisation are critical for understanding. In complex environments, effective change and growth should not be mandated but encouraged and facilitated through the introduction of appropriate attractors, incentives, diversity and the setting of flexible and porous boundaries. Promising emergent forms and patterns of behaviour should be rewarded and supported even when these are not what was originally anticipated [20].

The literature suggests that the different capabilities, experiences and needs of the elderly will require a range of different technical and social solutions to the problems of isolation and loneliness. In the exploratory research presented here we provided evidence of the complexity of this problem and the suitability of evoking Complexity Theory to indicate that simple imposed solutions are unlikely to be readily taken up by those in need of social connections. We will therefore look for solutions to emerge through a complex co-evolution of human and technical capability driven by those involved, namely the elderly, their families and carers. The principles of complexity theory will enable us to better understand this process.

\section{Research Approach}

Our research began with the review of literature summarised above and sources from a number of different fields; isolation and loneliness, contributions to the social wellbeing of isolated senior citizens, IT and the elderly, social media, Internet access and usability. There is little intersection between research in these different areas and we bring them together to inform our work through the lens of Complexity Theory which we have also described above.

Our exploratory research has been conducted in the following stages:

- A study of websites and online facilities created for and used by, Senior Australians

- Informal interviews with carers and service providers in the Aged Care Sector to determine from their experience, the social needs of the elderly and potential benefits of online social interaction among senior citizens 
- Focus groups with senior members of a local Computer Club on their use of the Internet and attitudes to social media.

We describe the conduct and results of this research below. The setting for this study is urban and regional Australia, which as a Western developed country, has a high level of IT and Internet use and the challenges of an ageing population. This is an opportune time to conduct a study in this area as a national broadband network is currently being rolled out to provide a high quality infrastructure to support new social multi platform media. Our Discussion uses the findings of this preliminary exploratory study to develop a research design for a wider study involving interventions in the form of the establishment, facilitation and assessment of online communities driven by the needs of groups of senior citizens.

\subsection{Observations of Senior Australians Online}

The first stage of the study involves an examination of the provision of ICT for seniors and its use and acceptance in Australia. Our exploratory study of existing approaches to online sites for seniors indicated that most were currently created top-down where government or civil 'experts' train, advise or organise older people who are assumed to have low digital skills and knowledge.

The Australian Government provides a website, seniors.gov.au, for senior citizens and associated activities. This site reflects a typical bureaucratic top-down approach that sees the government as having the responsibility to inform and educate its citizens with limited community engagement [9]. Much of the seniors' website is aimed at 50-70 year olds and assumes that most older people have a limited level of digital literacy. In Australia there are 160 public seniors' computer clubs which have a similar view and a focus on training, mentoring, technical support and provision of advice on security, privacy and awareness of IT pitfalls (http://www.ascca.org.au/). A typical club description is as follows:

"Brisbane Seniors Online Inc is a not-for-profit organization made up of volunteers who assist Brisbane's seniors to become competent with computers and to use them online. Most mentoring is done on a one-to-one basis in people's homes if they so choose. Since BSOL was formed in November 2000, our volunteer mentors have taught, or are teaching, some three thousand people over the age of 50 to become computer-literate - to access the Internet, send and receive emails and use word processing."

The Australian Seniors Computer Clubs Association (ASCCA)'s Google Group (http://groups.google.com.au/group/cyberascca) states that the main problems seniors face is the question of "how do I"? They offer an online help desk where members can post their questions and the experts of the Google group), along with other members, can offer suggestions on how to fix it. The University of the $3^{\text {rd }}$ Age (U3A) takes a similar simplistic view offering short online courses and many other useful resources for older people, especially those who are geographically, physically or socially isolated. The U3A Online website provides upto-date contacts for all Australian and New Zealand U3As as well as facilities for 
their members to exchange ideas, resources and information about regional U3A events. The information, including news items and links to many interesting websites, will also prove useful to other groups of older people.

With the move towards social networking, the ASCCA are investigating the use of the social networking website www.finerday.com which is more senior friendly than Facebook. The Australian government seniors' website is also beginning to try some online community building initiatives although most are not yet active. The Australian Seniors site says:

"In addition to providing a huge range of factual information relevant to older Australians, seniors.gov.au provides a wide range of exciting community-building features. These features enable you to interact with other people, with similar interests and ensures that this online resource reflects the opinions and addresses the issues of direct relevance to Australians over 50."

Features planned in the development are "Living History' (stories of where people were and what they were doing during a significant event in Australian history), a "Q\&A Forum", a "Meeting Place" (where topics of discussions could include such things as travel, genealogy and entertainment) and even "Online Games". Although these features are more creative there is still a top-down approach where the government controls, directs and manages the agenda.

In an attempt to find emergent communities of seniors we found Australian Seniors on linkedIn with 17 members and some recent discussion and an AustralianSeniors page on Facebook that had 43 likes but very little content. These seemed to be driven by a few individuals but not yet with a critical mass to be called a community. This suggests that while online communities of seniors may follow similar patterns of other such groups, there is a need to investigate where they may differ and have more specific requirements and challenges.

\subsection{Advice from those working in the Aged Care Sector}

As part of a set of interviews conducted during a separate research project, carers and service providers in the Aged Care Sector were asked for their comments and advice on our proposed project. Their responses confirmed the following:

- That the emphasis on current e-health research was on technical and medical issues

- That loneliness was a major problem as people aged and had a significantly affect on their health and wellbeing, often leading to depression.

- That IT and the Internet could be used in a solution to the isolation that often increased as people aged but that there would have to be a variety of systems needed to suit people in different circumstances and conditions.

Many of those interviewed belonged to a Dementia Support Network and indicated that dementia patients would be a particular challenge. However they also noted that as people age a whole range of special needs develop which may impact 
on their ability to use a standard computer. This provides evidence for the complexity of the problem.

\section{The digital literacy and attitudes of Senior Citizens}

In order to gauge the potential for senior citizens to use social media and assess their attitudes to doing this, we held a discussion on this topic with members of a Seniors Computing Club at their invitation. In keeping with our intention to take an exploratory approach to this phase of the research we followed the nondirective, 'affinity group discussion approach of Hugh McKay, a renowned social commentator in Australia. This method [22] uses a naturally existing social group (in our case members of the computing club) meeting together in their natural habitat (the club's monthly meeting), to engage in informal and unstructured conversation about the topic of the research. An inductive analysis of the audio recording of this conversation involved the identification of themes and individual perceptions by the researchers and revealed the following:

Several of the members, mostly those who had used computers for years and were respected as experts by other members were quite antagonistic towards the use of social media. They saw applications such as Facebook and Twitter as trivial exercise in social banter. As one said "I can't see the sense of it, my time is too valuable to waste on that" and "if my daughter wants to share a picture with me she should just attach it to an email". Others, however, began to describe how they used Facebook and Skype to keep in touch with family. Another called himself "a stirrer" and saw how blogging and online discussions would be attractive for him. Another advocated using Internet tools to put his life story online for his decedents to read once he is gone. One very elderly gentleman then described his extensive use of social media for all sorts of activities that he combines with his volunteer work and interests. Right at the end one elderly lady describe her experiences with isolation and said that if online communities could help she would be all for it. Lots of the general discussion described how they would come across different applications on the Internet and see how they could be useful for something they were doing. This demonstrated the emergent nature of how things happen in this regard and support our intention to follow a "bottom up" approach to the interventions we plan for the next phase of our research.

\section{Discussion of Next Steps}

As indicated above our research, seeks answers questions on the potential use of information systems in meeting the social needs of isolated elderly users? The results of the literature review and exploratory study described above, combined with our understand of emergent processes from Complexity Theory, confirmed our commitment to the following propositions in answering those questions: 
- That overcoming loneliness and isolation experienced in old age would have positive benefits for the national health system

- That one component of the e-health program could be the use of the Web to connect isolated elderly and overcome the negative effects of loneliness

- That this approach would need to take a bottom-up approach to engage citizens in the process

- That a diverse range of socio-technical systems and community activities would emerge as the program progressed

- That Complexity Theory constructs can underpin research in this area.

According to Kurtz and Snowden [20] and Mitleton-Kelly [24] the processes of emergence and co-evolution as understood by Complexity Theory cannot be planned but can be encouraged through the imposition of 'attractors' with suitable 'boundaries'. Precise outcomes cannot be known in advance but positive outcome are likely if the attractors and boundaries are chosen well. We will thus follow an action research methodology for the next phase of this research where interventions will be carried out to provide opportunities, advice, incentives and resources (i.e. attractors) among groups of senior Australians to form online communities bounded by the technologies that suit them and are available. A "bottom up" approach will be followed to engage participants at all stages and the emergent outcomes will be studied, evaluated and reported.

The creation of new communities is best understood by the principles of complexity as diversity, creativity, self-organization and unanticipated outcomes are key elements in the co-creation of an innovative environment. The distinguishing characteristic of complex co-evolving systems is their ability to create new order. In human communities this may take the form of new ways of communicating, acting, thinking, and relating or even the creation of a different culture or a new organizational form [24 25].

In our study the application of Complexity Theory can guide our analysis of the emergence and facilitation of self-directed online communities of senior citizens as well as a participatory emergent approach to evolution of the diversity of suitable tools and their interfaces. Members of such communities require a level of digital information literacy beyond simple computing skills to the ability to $a c$ cess, interpret, connect, manipulate, visualise and create digital content. The computer itself has become almost ubiquitous so that the traditional concepts of usability and acceptance give way to those of real engagement and emersion in a merged interconnected physical and virtual world.

We will therefore apply concepts of Complexity Theory to our research design of interventions involving online communities of senior citizens and relate these to their subjective well-being which Wiesmann and Hannich [32] have developed as an indicator for successful ageing. These authors adopted the perspective that a sense of coherence plays a key role for psychological adaptation. The findings corroborate the idea that the sense of coherence (i.e. integrated and holistic) creates, or maintains, a form of psychological integrity as represented by subjective well-being. Our research will take this idea into the digital online environment. 


\section{Conclusion}

The literature review and early findings of this research suggest that the use of social media by senior citizens may be beneficial to their wellbeing, overcoming isolation and loneliness as they become more housebound. The creation of online communities that would engage the elderly is however unlikely to succeed if imposed on them and so we turn to concepts from Complexity Theory such as emergence to guide proposed research in this area.

\section{References}

1. Anon. (2010). Older Adults' Use Of Social Media Nearly Doubles. Telecommunications Report, 76(18): 34-34.

2. AGD (2010). Australia to 2050: future challenges. Attorney-General's Department Commonwealth of Australia, Canberra.

3. ADHA (2011). Older Australians and the Internet: bridging the digital divide. National Seniors Productive Ageing Centre (NSPAC), Australia Department of Health and Ageing.

4. AHRC (2000). Accessibility of electronic commerce and new services and information technologies for older Australians and people with a disability. Report of the Australian Human Rights Commission, Canberra.

5. Ballantyne, A., Trenwith, L., Zubrinich, S., Corlis, M. (2010). 'I feel less lonely': what older people say about participating in a social networking website. Quality in Ageing \& Older Adults, 11(3): 25-35

6. Budde, P. (2009). Australia: The National Broadband Network. PressReleasePoint. Posted November $4^{\text {th }}, 2009$ by BuddeComm. http://www.pressreleasepoint.com/print $/ 391710$

7. Budde, P. (2010). Australia: The National Broadband Network. BuddeBlog. July 2010 http://www.buddeblog.com.au/frompaulsdesk/australia-the-national-broadband-network

8. Campbell, R. (2010). Giving it all she's got. Northern Echo. [Darlington (UK)] 23 Oct .

9. Chadwick, A., (2011). Explaining the Failure of an Online Citizen Engagement Initiative: The Role of Internal Institutional Variables. Journal of IT \& Politics, 8, 21-40.

10. Chung, J. E., Park, N. et al. (2010). Age differences in perceptions of online community participation among non-users: An extension of the Technology Acceptance Model. Computers in Human Behavior, 26(6): 1674-1684.

11. Coughlan S. (2011). Loneliness is 'hidden killer' of elderly http://www.bbc.co.uk/news/education-12324231

12. Dickinson, A., Gregor, P. (2006). Computer use has no demonstrated impact on the wellbeing of older adults. International Journal of Human Computer Studies, 64:744-753.

13. Etchemendy E., Baños, R.M., Botella, C., Castilla, D., Alcañiz, M., Rasal, P., Farfallin, L. (2011). An e-health platform for the elderly population: The butler system. Computers \& Education, 56(1), pp 275-279.

14. Erickson, L (2011) "Social media, social capital and seniors: The impact of Facebook on bonding and bridging social capital of individuals over 65", AMCIS Proceedings Paper 85.

15. Erickson, J. \& Johnson, G.M. (2011). Internet Use and Psychological Wellness during Late Adulthood. Canadian Journal on Aging, 30(2): 197-209.

16. Ford, G.; Ford S. (2009). Internet use and depression among the elderly. Phoenix Center Policy Paper, Number 38. October 2009.

17. Golden J., Conroy R., Bruce I., Denihan A., Greene E., Kirby M., Lawlor B. (2009). Loneliness, social support networks, mood and wellbeing in community-dwelling elderly. International Journal of Geriatric Psychiatry, 24/7, pp 694-700. 
12 Lois Burgess Helen Hasan Carole Alcock

18. Interlandi, J. (2011.) Facebook-like portal helps teens with Crohn's Collaborate on medical research. Scientific American, November 2011.

19. Kehoe, J.; Bednall, E. T. C. et al. (2009). Training adult novices to use computers: Effects of different types of illustrations. Computers in Human Behavior, 25(2): 275-283.

20. Kurtz, C., Snowden D. (2003). The new dynamics of strategy: Sense-making in a complex and complicated world. IBM Systems Journal, 42/3, 462-483.

21. Madden, M. (2010). Older adults and social media: social networking use among those ages 50 or older nearly doubled over the past year. Pew Internet \& American Life Project: Pew Research Center: http:// pewinternet.org/Reports/2010/Older-Adults-and-Social-Media.aspx

22. McKay H. (2011). The unfocussed group discussion technique. Presentation at the IIBSoR Retreat - Wednesday 6 July 2011.

23. Mellor, D., Firth, L., Moore, K. (2008). Can the Internet improve the well-being of the Elderly? Ageing International, 32:25-42.

24. Mitleton-Kelly, E. (2005). A Complexity approach to co-creating an innovative environment. World Futures, 62/3, pp 223-239.

25. Mitleton-Kelly, E. 2011: A Complexity Theory Approach to Sustainability: A Longitudinal Study in Two London NHS Hospitals. Learning Organization: An Int' Journal, 18(45), 53.

26. Norrie, J. (2012). Loneliness on the rise as our cities atomise. http://theconversation.edu.au/loneliness-on-the-rise-as-our-cities-atomise-6068

27. Norval, C. Arnott, J. Hine, N. Hanson, V. (2011) 'Purposeful Social Media as Support Platform: Communication Frameworks for Older Adults Requiring Care' ATTACH, Dublin,

28. Palmer, S. (2011). Where do I start? Female seniors and the Internet. Council on the Aging (WA). Australian Communications Consumer Action Network, Sydney.

29. Parry, D. (2011). Mobile Perspectives on: Teaching: Mobile Literacy. EDUCAUSE Review, March/April 2011 46(2): 14-18.

30. Pew Internet (2010). Spring Change Assessment Survey 2010. Princeton Survey Research Associates International for Pew Research Center: April29 - May 30 , 2010.

31. Phoenix Center (2009). Press Release: Internet cuts depression among senior citizens. Thursday, October 15, 2009. http://www.phoenix-center.org

32. Sum, S., Mathews, R., Pourghasem, M., \& Hughes, I. (2009). Internet Use as a Predictor of Sense of Community in Older People. CyberPsychology \& Behavior, 12(2), 235-239.

33. Wiesmann, U., Hannich, H. (2008). A salutogenic view on subjective well-being in active eld erly persons. Aging \& Mental Health, 12/1 pp 56-65.

34. Xie, B., Jaeger, P. (2008). Computer training programs for older adults at the Public Library. Public Libraries, Sept/Oct 2008: 52-59.

35. Xie, B., Bugg, J. (2009). Public library computer training for older adults to access highquality Internet health information. Library \& Information Science Research, 31, 155-162. 